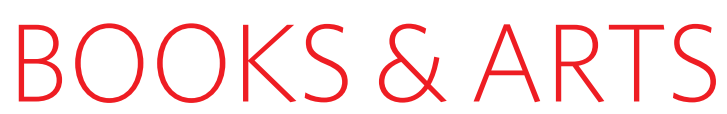

\title{
Expanding evolution
}

\section{A broader view of inheritance puts pressure on the neo-darwinian synthesis.}

\author{
Evolution in Four Dimensions: Genetic, \\ Epigenetic, Behavioral, and Symbolic \\ Variation in the History of Life \\ by Eva Jablonka \& Marion J. Lamb \\ Bradford Books: 2005. 462 pp. \\ $\$ 34.95, £ 22.95$
}

\section{Massimo Pigliucci}

There have been rumblings for some time to the effect that the neo-darwinian synthesis of the early twentieth century is incomplete and due for a major revision. In the past decade, several authors have written books to articulate this feeling and to begin the move towards a second synthesis. David Rollo, in his book Phenotypes (Kluwer, 1994), was among the first to attempt to bring the focus back to the problems posed by phenotypic evolution. In Phenotypic Evolution (Sinauer, 1998), Carl Schlichting and I framed the debate in terms of the integration of development, environment and genetics by articulating the concept of "developmental reaction norms". Stephen Jay Gould then produced an overly long (and at times acrimonious) sketch of the new synthesis in The Structure of Evolutionary Theory (Harvard University Press, 2002). Finally, Mary-Jane West-Eberhard, in Developmental Plasticity and Evolution (Oxford University Press, 2003), greatly expanded on my book and the one by Rollo, producing the most comprehensive alternative account of evolutionary theory yet. Evolution in Four Dimensions by Eva Jablonka and Marion Lamb is the most recent addition to this genre, and contributes yet another valuable perspective to the discussion.

Jablonka and Lamb provide a framework that includes not one but four sources of inheritance in living organisms: there is the standard genetic one, based on nucleic acids such as DNA and RNA; there are epigenetic inheritance systems, such as (but not limited to) chromatin marking systems and RNA-interference systems for gene silencing; third, there are behavioural inheritance systems, including behaviour-influencing substances (think pheromones) and social learning (both imitative and not); finally, humans have also developed a symbolic inheritance system based on the ability to communicate by manipulating symbols.

The authors argue that there is more to heredity than genes; that some hereditary variations are non-random in origin; that some acquired information is inherited; and that evolutionary change can result from instruction' as well as selection. This may sound rather revolutionary, even preposterously close to lamarckism. But Jablonka and Lamb build on evidence from standard research in evolutionary and molecular biology, and their case should be examined on its merits, rather than being dismissed by a knee-jerk reaction.

Consider the charge of lamarckism. Jablonka and Lamb happily embrace the term, but with one important qualification. As they correctly point out, there are at least two very distinct meanings of the word. Most biologists associate lamarckism with the idea of direct adaptive feedback from the soma to the germ line. That version of lamarckism is dead, killed off by our understanding of

IMAGE
UNAVAILABLE
FOR COPYRIGHT
REASONS

Down the generations: symbolic systems such as the written word provide an important means of cultural inheritance. molecular biology, and nobody is attempting to revive it.

The second meaning is actually closer to the core of Lamarck's ideas, which are rarely, if ever, read by modern biologists. The suggestion is that some heritable, adaptive changes come not from natural selection, but from the action of evolved internal systems that generate non-random 'guesses' in response to environmental challenges. Examples are not hard to find, contrary to the assumed wisdom of standard neo-darwinism. Consider the existence of 'hotspots' that make mutations in certain regions of the genome much more likely than in others. Or the impressive ability of some bacteria to increase the mutation rate of a specific gene involved in the metabolism of a given amino acid when that amino acid becomes scarce in the environment.

Jablonka and Lamb are surely taking a gamble in labelling their position as lamarckist, but they are correct to point out that no modern biologist is a darwinist in the sense Darwin would have understood - not least because Darwin included a lamarckian mechanism of the first (now frowned upon) type in his theory, as he had no solution to the problem of heredity.

If one accepts this bold, expanded version of heredity and evolution, it turns out that evolution can proceed very rapidly and phenotypic modification can precede genetic changes something also suggested by several of the authors of the other books mentioned above. Indeed, changes at the genetic level will often simply stabilize adaptive modifications that are initiated through phenotypic plasticity, epigenetic control mechanisms, or behavioural and symbolic means. This is a framework that would greatly help to solve old problems in evolutionary biology, such as the origin of novel structures, and even the appearance of what 'intelligent design' proponents refer to, rather nonsensically, as irreducible complexity'. This wouldn't require the abandonment of neo-darwinism, but rather its expansion beyond what Ernst Mayr contemptuously labelled 'beanbag genetics.

The irony, as Jablonka and Lamb point out, is that empirical evidence for 
the importance of epigenetic inheritance systems comes from the partial failure of the originally ultra-reductionist, gene-centred approach that gave us genomics. It is becoming increasingly clear that the interesting stuff is going on at the level of large gene networks, not of individual genes, partly because there is widespread functional redundancy in the genome. This is why we are seeing an astounding proliferation of 'omics' - after genomics, we have had proteomics, metabolomics and even phenomics, whatever that may mean.

Evolution in Four Dimensions also features a series of fictitious dialogues between the authors and a character named Ifcha Mistabra, which is Aramaic for "the opposite conjecture". This is a time-honoured philosophical device (used in the platonic dialogues, and in David Hume's dialogues on natural religion) for considering possible objections to one's arguments and discussing them in a literary way. Some scientists may feel alienated by this device, but I found it refreshing to read a science book that is a conscious attempt at good literature. I really don't understand why so many of my colleagues equate boredom with seriousness.

The clamour to revise neo-darwinism is becoming so loud that hopefully most practising evolutionary biologists will begin to pay attention. It has been said that science often makes progress not because people change their minds, but because the old ones die off and the new generation is more open to novel ideas. I therefore recommend this and the other books I mentioned on the future of evolutionary theory to the current crop of graduate students, postdocs and young assistant professors. They'll know what to do. Massimo Pigliucci is in the Department of Ecology and Evolution, State University of New York at Stony Brook, 650 Life Science Building, Stony Brook, New York 11794, USA.

\section{Death and taxas}

\section{Insect Diversity Conservation \\ by Michael J. Samways \\ Cambridge University Press: 2005. 342 pp. \\ $€ 30, \$ 55$ (pbk); $€ 60, \$ 110$ (hbk)}

\section{Norman Myers}

We really needed this book ten years ago when it would have illuminated an urgent but largely uninvestigated challenge of conservation biology. We have long been aware that the great bulk of the mass extinction currently under way is made up of insects, yet we have had only a meagre grasp of the details.

We have 'guesstimated' that $80 \%$ of the roughly 10 million species on the planet are insects. Yet we know so little about them that we haven't even located the main concentrations of insects (although one strong contender is the canopies of tropical forests). We know next to nothing about their natural histories or other key characteristics. And most important, we have only vague clues about their conservation status: how many species should be classified as threatened? Are species being eliminated at rates matching those for mammals and birds - that is, hundreds or even thousands of times faster than before modern humans appeared? All these questions are addressed in this compendious book.

It's true that a few taxa are well documented, notably butterflies (about 20,000 species), ants $(8,000)$, dragonflies $(6,000)$ and tiger beetles $(25,000)$. But these total only some 60,000 , and we cannot say how far they serve as indicator species to throw light on the rest. Fortunately, we can gain some insight by drawing on the congruence relationships of insects with plants. If we accept (gulp) that there are at least 300,000 species of plant and 8 million species of insect, that works out at one plant species that would surely be less damaging than losing half of all insect species with their pollinating services: our agricultural crops could be in trouble within short order. We live in a bugdriven world.

All this is dealt with in splendid detail in this book by Michael Samways, a leading entomologist at Stellenbosch University in South Africa. He starts out with the rationales for insect conservation, then considers such esoteric factors as evolutionary radiation, flight mechanisms, polymorphisms and taxonomic challenges. He reviews insects' roles as keystone organisms, soil modifiers, pollinators, parasitoids and predators, and disease vectors. He considers insect survival in a fast-changing world, assessing such issues as environmental contamination, agricultural encroachment, deforestation, threats from invasive aliens, biological controls, genetic engineering, climate change and future evolution, as well as synergized interactions between these factors. The book concludes with an extended evaluation of conservation strategies, including reserve selection, plant and animal surrogates, phylogenetic considerations, inventorying and monitoring, species restoration, triage conservation (focusing efforts on the top priorities), and biodiversity hotspots as applied to insects.

Samways displays a flair for engaging asides, such as his comment on insects' fecundity: "One gravid aphid, left to reproduce with zero mortality, will, after one year, cover the globe with an aphid layer over $140 \mathrm{~km}$ thick."

There are very few insect books of such expansive scope, and this one could be a standard text for years. It will be welcomed by specialists in entomology, biodiversity, mass extinction, evolution and half-a-dozen associated fields. But it is much more than an expert book for experts; it should appeal to everyone interested in the fast-diminishing biodiversity of our planet. All in all, this is an expensive book that is excellent value.

Norman Myers is honorary visiting fellow at Green College, Oxford University, Upper Meadow, Quarry Road, Oxford OX3 8FS, UK.

IMAGE

UNAVAILABLE FOR COPYRIGHT REASONS 